\title{
Desmídias pseudofilamentosas na comunidade ficoperifítica do Reservatório de Rosana, Bacia do Rio Paranapanema, Brasil ${ }^{1}$
}

\author{
SIRLENE APARECIDA FELISBERTO² e LILIANA RODRIGUES 33,4
}

(recebido: 19 de março de 2010; aceito: 24 de março de 2011)

\begin{abstract}
Pseudofilamentous desmids of the phycoperiphytic community of the Rosana Reservoir, Paranapanema River basin, Brazil). This study aimed to make an inventory species of periphytic pseudofilamentous desmids from three regions of the Rosana Reservoir, southern Brazil. Samples were collected in autumn and winter periods at different sites along the river-dam axis of the reservoir (fluvial, intermediate and lacustrine regions). The substrates (petioles of Eichhornia azurea Kunt) were collected in the littoral. Thirteen taxa of phycoperiphytic pseudofilamentous desmids (Desmidiaceae) were distributed in five genera: Desmidium C. Agardh (3), Hyalotheca Ehrenberg (1), Onychonema Wallich (3), Sphaerozosma Corda ex Ralfs (1) and Spondylosium Brébisson ex Kützing (5). Considering both sampling periods, in the lacustrine region it was recorded the highest number of species, i.e. eight in autumn and ten in winter. Independently of the sampled period, pseudofilamentous desmids were not found in the fluvial region, well as in the intermediate region in the autumn.
\end{abstract}

Key words - Desmidiales, periphytic algae, taxonomy

RESUMO - (Desmídias pseudofilamentosas na comunidade ficoperifítica do Reservatório de Rosana, Bacia do Rio Paranapanema, Brasil). Este trabalho, objetivou o conhecimento das espécies de desmídias pseudofilamentosas da comunidade perifítica de três regiões do Reservatório de Rosana, sul do Brasil. As amostras foram coletadas nos períodos de outono e inverno em diferentes pontos ao longo do eixo rio-barragem do reservatório, abrangendo a região fluvial, intermediária e lacustre. Os substratos coletados, sempre na região litorânea e em todos os pontos de coleta, foram pecíolos de Eichhornia azurea Kunth. As desmídias pseudofilamentosas (Desmidiaceae) foram representadas por 13 táxons distribuídos em cinco gêneros: Desmidium C. Agardh (3), Hyalotheca Ehrenberg (1), Onychonema Wallich (3), Sphaerozosma Corda ex Ralfs (1) e Spondylosium Brébisson ex Kützing (5). Considerando os dois períodos amostrados, na região lacustre foi registrado maior número de espécies, sendo oito no outono e dez no inverno. Independentemente da época de coleta, na região fluvial não houve ocorrência de desmídias pseudofilamentosas, da mesma forma que na região intermediária no período do outono.

Palavras-chave - algas perifíticas, Desmidiales, taxonomia

\section{Introdução}

Alga é um termo popular que reúne um universo de organismos (talófitos e protistas) fotossintetizantes, encontrados em uma grande diversidade de ambientes, principalmente em sistemas aquáticos continentais (Round 1983, Bicudo \& Menezes 2006). No perifíton, as algas apresentam relevante importância nos sistemas aquáticos, pois além de atuarem como um dos principais produtores na cadeia alimentar, também estão diretamente envolvidas na ciclagem de nutrientes produzida no ambiente (Horne \& Goldman 1994, Lowe \& Pan 1996).

1. Parte da dissertação de mestrado da primeira autora, Programa de Pós-Graduação em Ecologia de Ambientes Aquáticos Continentais, Universidade Estadual de Maringá, PR, Brasil.

2. Universidade Federal de Goiás, Instituto de Ciências Biológicas, Programa de Pós-Graduação em Ecologia e Evolução, Campus Samambaia, Caixa Postal 131, 74001-970 Goiânia, GO, Brasil.

3. Universidade Estadual de Maringá, Programa de Pós-Graduação em Ecologia de Ambientes Aquáticos Continentais, Núcleo de Pesquisas em Limnologia, Ictiologia e Aquicultura, Bloco G-90, Av. Colombo 5790, 87020-900 Maringá, PR, Brasil.

4. Autor para correspondência: 1rodrigues@nupelia.uem.br
Em termos morfológicos, esses organismos desenvolvem-se como células isoladas, agregados de células (indivíduos coloniais de diversos grupos) ou filamentosos. Dentre os filamentosos há aqueles que não se enquadram como verdadeiros, sendo assim considerados como pseudofilamentosos, devido ao arranjo linear das células em que comumente as paredes se encostam, mas permanecem como células individuais. Dentre esses se encontram representantes da família Desmidiaceae.

As desmídias constituem um grupo representativo em número de gêneros e espécies. Os trabalhos enfocando a taxonomia de Desmidiaceae realizados especificamente para o Reservatório de Rosana resumem-se aos de Bicudo et al. (1992, 1993). Estes estudos utilizaram dados da comunidade fitoplanctônica e nenhum deles enfocou exclusivamente as desmídias pseudofilamentosas. Estas, por sua vez, quando em comunidades ficoperifíticas, são citadas em três trabalhos (Biolo et al. 2008, Bortolini et al. 2008, Felisberto \& Rodrigues 2008).

Considerando a importância em se conhecer a biodiversidade aquática, este estudo teve como objetivo identificar e descrever as espécies de desmídias 
pseudofilamentosas (Desmidiaceae) do perifíton de três distintas regiões do Reservatório de Rosana (bacia do Rio Paranapanema) em dois períodos do ano.

\section{Material e métodos}

O Reservatório de Rosana está situado na Bacia do Rio Paranapanema, que é o limite entre os Estados de São Paulo e Paraná (coordenadas $22^{\circ} 36^{\prime}$ S e $52^{\circ} 50^{\prime}$ W, figura 1). As três estações de coleta foram estabelecidas em diferentes pontos ao longo do eixo rio-barragem do reservatório, abrangendo a região fluvial, intermediária e lacustre, nas proximidades dos Municípios de Teodoro Sampaio, Euclides da Cunha e Rosana, respectivamente. Este reservatório apresenta $220 \mathrm{~km}^{2}$ de área, $116 \mathrm{~km}$ de comprimento, profundidade de $12 \mathrm{~m}$ na região fluvial e intermediária e de $30 \mathrm{~m}$ na lacustre. Seu leito é composto por rocha basáltica.
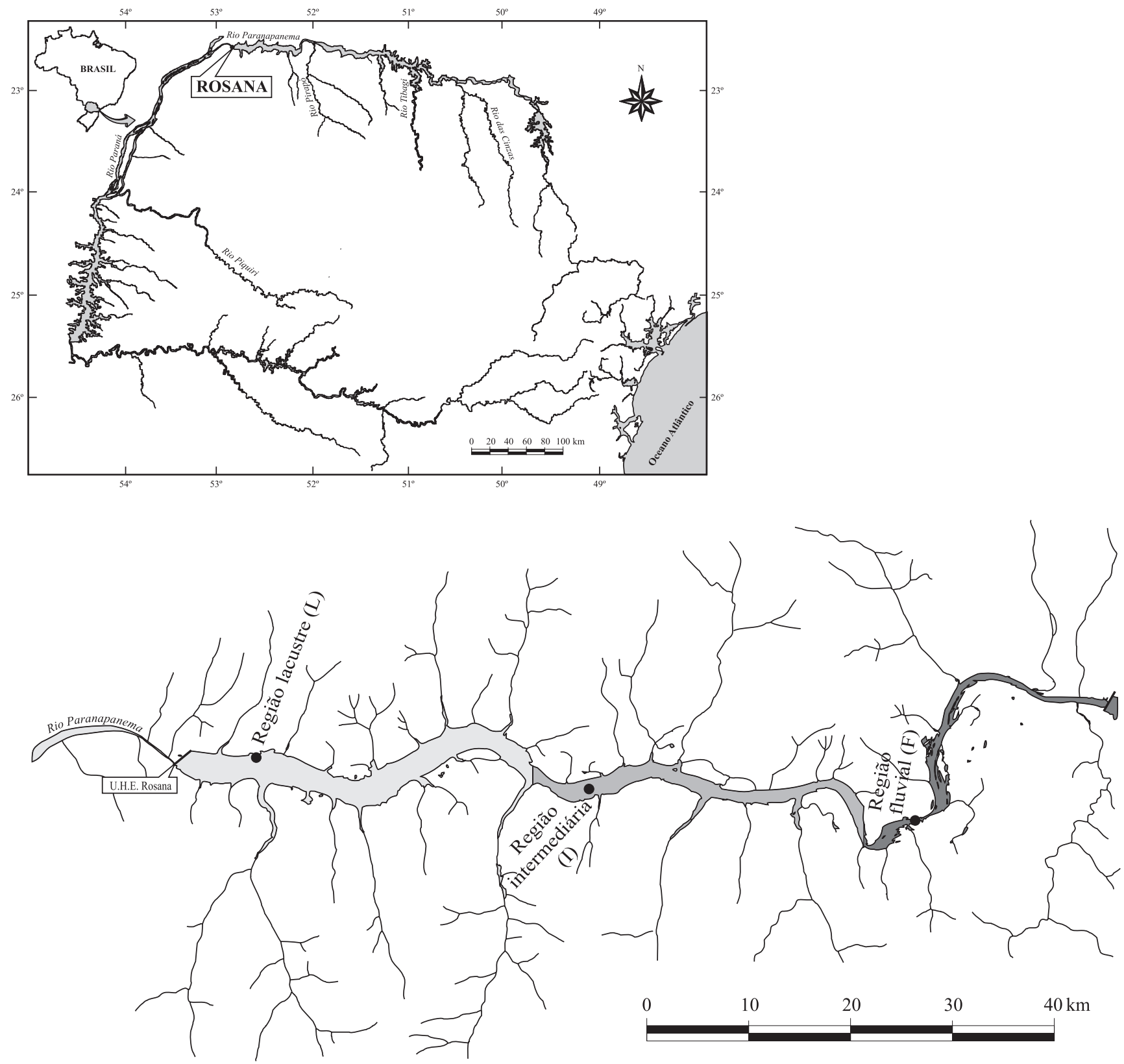

Figura 1. Localização do Reservatório de Rosana (Bacia do Rio Paranapanema), Paraná/São Paulo, Brasil. Regiões fluvial (F), intermediária (I), lacustre (L).

Figure 1. Location of the Rosana reservoir (Paranapanema River Basin), Paraná/São Paulo States, Brazil. Fluvial (F), intermediate (I), lacustrine (L) regions. 
Duas coletas foram realizadas no ano de 2002, nos períodos de outono ( 9 a 11 de abril) e inverno (27 a 29 de agosto), nas regiões fluvial, intermediária e lacustre do Reservatório de Rosana. No ambiente estudado há diferentes tipos de plantas aquáticas, porém os substratos coletados, sempre na região litorânea e nas três regiões de coleta, foram pecíolos de Eichhornia azurea Kunth, totalizando seis amostras em triplicata (três pecíolos de plantas diferentes, amostras independentes, por região), partindo de uma análise quantitativa e complementada com análise qualitativa. $\mathrm{O}$ perifíton coletado foi removido do substrato com lâmina de barbear e jatos de água destilada, transferido para frascos de $150 \mathrm{~mL}$, fixado e preservado com solução de Transeau.

O estudo taxonômico das desmídias foi realizado pela análise de lâminas temporárias, até não mais serem registradas novas ocorrências de espécies. As características morfológicas e métricas dos táxons foram registradas sempre que possível analisando-se a variação dos caracteres em amostras populacionais, exceto quando o táxon apresentou ocorrência rara (dois indivíduos em amostras diferentes). Esse procedimento e as ilustrações, foram realizados em microscópio binocular, acoplado com ocular micrometrada e câmara clara (Nikon), em objetivas de 400 e 100 vezes.

O sistema de classificação adotado foi o proposto por Förster (1982) e as principais bibliografias utilizadas para identificação foram Förster $(1969,1974)$, Croasdale et al. (1983), Sophia (1982, 1984, 1987), De Lamonica-Freire (1992), Sophia \& Dias (1996). As amostras estão depositadas no Herbário da Universidade Estadual de Maringá (HUM) sob as numerações de 15362 a 15367.

\section{Resultados e discussão}

As desmídias pseudofilamentosas foram representadas por 13 táxons (tabela 1) na comunidade ficoperifítica em três regiões do Reservatório de Rosana (fluvial, intermediária e lacustre) e duas estações do ano (outono e inverno).

Do total de seis amostras analisadas, considerando as três regiões do Reservatório de Rosana, encontramos representantes de Desmidiaceae pseudofilamentosas em quatro amostras, distribuídos nos gêneros: Desmidium C. Agardh, Hyalotheca Ehrenberg, Onychonema Wallich, Sphaerozosma Corda ex Ralfs e Spondylosium Brébisson ex Kützing. Spondylosium foi o gênero representado por maior número de táxons.

Segue a chave de identificação e descrição das espécies e variedades identificadas, sendo as mesmas enquadradas na Classe Zygnemaphyceae, ordem Desmidiales, família Desmidiaceae.

Tabela 1. Distribuição espacial e temporal das desmídias pseudofilamentosas (Desmidiaceae, Zygnemaphyceae) no Reservatório de Rosana. ( $\mathrm{F}=$ Regiões fluvial; $\mathrm{I}=$ intermediária; $\mathrm{L}=$ lacustre).

Table 1. Spatial and temporal distribution of pseudofilamentous desmids (Desmidiaceae, Zygnemaphyceae) of the Rosana Reservoir. $(\mathrm{F}=$ fluvial region; $\mathrm{I}=$ intermediate region; $\mathrm{L}=$ lacustrine region).

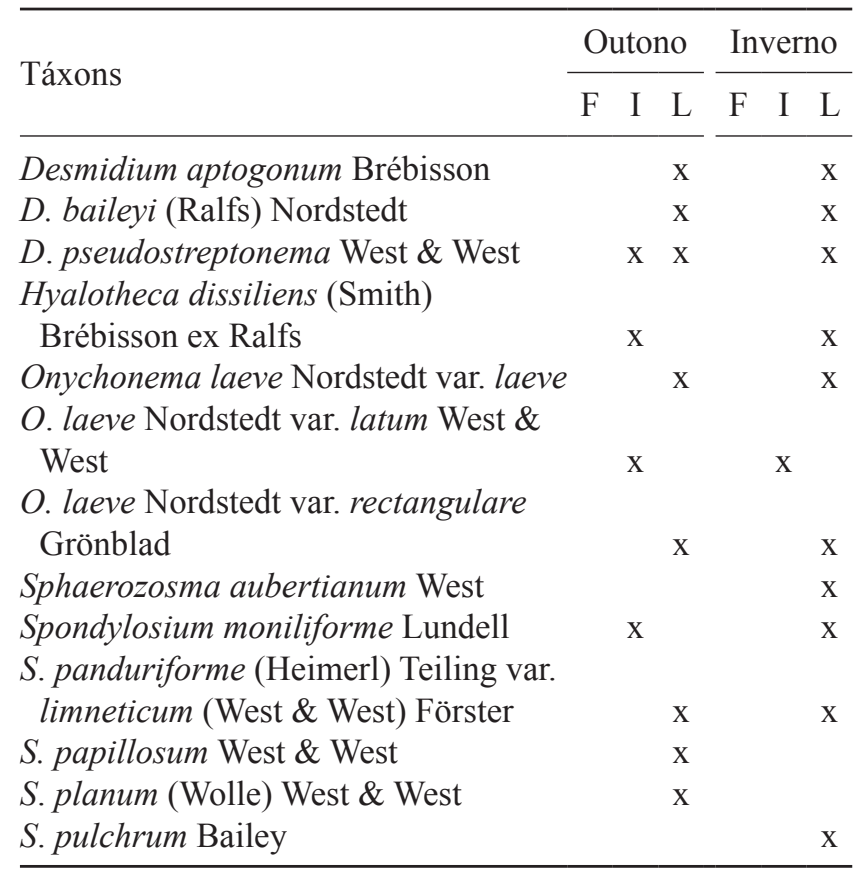

Chave de identificação para os táxons encontrados no Reservatório de Rosana:

1. Filamento torcido

2. Célula com comprimento superior a $30 \mu \mathrm{m}$ Spondylosium pulchrum

2. Célula com comprimento inferior a $30 \mu \mathrm{m}$

3. Constrição mediana leve a moderada

4. Semicélulas retangulares; parede celular lisa Desmidium aptogonum

4. Semicélulas oblongas; parede celular pontuada Desmidium pseudostreptonema

3. Constrição mediana profunda

5. Parede de cada semicélula com duas fileiras horizontais de poros estendidos em toda sua extensão Sphaerozosma aubertianum

5. Parede de cada semicélula lisa ou outro tipo de ornamentação, exceto poros 
6. Células mais largas que longas; presença de dois processos unindo as células Onychonema laeve var. laeve

6. Células mais longas que largas; ausência de processos Spondylosium moniliforme

1. Filamento não torcido

7. Constrição mediana rasa ou suave

8. Semicélulas circulares, com ampla mucilagem no entorno Spondylosium

8. Semicélulas retangulares; ausência de mucilagem espessa

9. Margens laterais das células paralelas, às vezes com leve ondulação; parede pontuada Desmidium baileyi

9. Margens laterais das células convexas, unidas por seus ápices formando filamentos constritos nas junções; parede celular lisa Hyalotheca dissiliens

7. Constrição mediana profunda

10.Processos de conexão entre células vizinhas presentes

11. Célula com $20 \times 28-29 \mu \mathrm{m}$ Onychonema laeve var. latum

11.Célula com $16-19 \times 18,4-23 \mu \mathrm{m}$ Onychonema laeve var. rectangulare 10.Processos de conexão entre células vizinhas ausentes

12.Parede celular lisa Spondylosium planum 12.Parede celular com margens laterais com papilas Spondylosium papillosum

Desmidium aptogonum Brébisson ex Kützing, Spec. Alg., p. 190. 1849.

Figura 2

Filamento torcido; célula $18,6-20,4 \times 28-31 \mu \mathrm{m}$, largura do istmo: $25,7-27,1 \mu \mathrm{m}, 1,3-1,6$ vezes mais larga que longa; sem projeções espinhosas; constrição mediana leve, sendo linear aberto; semicélulas retangulares, margem superior com depressão, margens laterais com 1 intumescência proeminente; parede celular lisa.

Comentários: Os exemplares analisados ocorreram apenas uma vez na região lacustre em ambos os períodos, porém com a mesma amplitude de medidas celulares. Desta forma optou-se por identificá-lo em nível específico apesar de Croasdale et al. (1983) registrarem indivíduos desta espécie com a relação comprimento/ largura maiores (duas vezes mais larga que longa) que o material analisado neste trabalho.

Material examinado: BRASIL. PARANÁ: Rosana: Reservatório de Rosana, 11-IV-2002, S.A. Felisberto s.n. (HUM15364); 29-VIII-2002, S.A. Felisberto s.n. (HUM15367).

Desmidium baileyi (Ralfs) Nordstedt, Acta Univ. Lund. 16: 4. 1880.

Figuras 3A, B

Filamento não torcido; célula 19-24,4 × 20-22 $\mu \mathrm{m}$, 1-1,2 vezes mais larga que longa; constrição mediana extremamente suave, com leve ondulação, seno mediano reduzido, praticamente imperceptível; semicélulas retangulares, margem superior com depressão, projetada nos ângulos formando processo de conexão em cada ângulo, margens laterais paralelas, as vezes com leve ondulação; parede pontuada.

Comentários: Nesta espécie foi observado que as margens laterais são onduladas, como também documentado por Sophia (1982) para material proveniente do Estado do Rio de Janeiro, porém não observado por De-Lamonica-Freire (1992) para material do Estado do Mato Grosso.

Material examinado: BRASIL. PARANÁ: Rosana: Reservatório de Rosana, 11-IV-2002, S.A. Felisberto s.n. (HUM15364); 29-VIII-2002, S.A. Felisberto s.n. (HUM15367).

Desmidium pseudostreptonema West \& West, Trans. Linn. Soc. London, Bot., II, 6(3): 193. pl. 22, figs. 35-37. 1902a.

Figura 4

Filamento torcido; célula 17,5-21,2 × 28,8-32,5 $\mu \mathrm{m}$, largura do istmo: $16,8-22,2 \mu \mathrm{m}, 1,5$ vezes mais larga que longa; constrição mediana moderada, seno aberto; semicélulas oblongas, margem superior com depressão, projetada nos ângulos, com um processo curto de conexão, margens laterais arredondadas; parede pontuada.

Material examinado: BRASIL. PARANÁ: Euclides da Cunha: Reservatório de Rosana, 10-IV-2002, S.A. Felisberto s.n. (HUM15363); Rosana: Reservatório de Rosana, 11-IV-2002, S.A. Felisberto s.n. (HUM15364); 29-VIII-2002, S.A. Felisberto s.n. (HUM15367). 

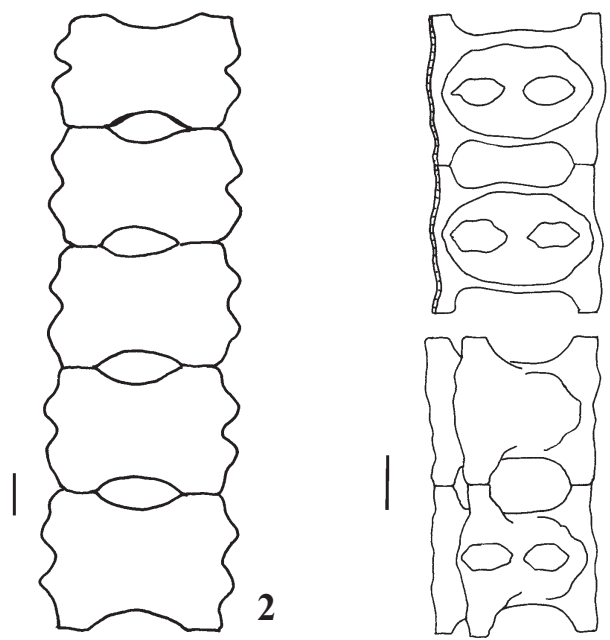

$3 \mathbf{A}$
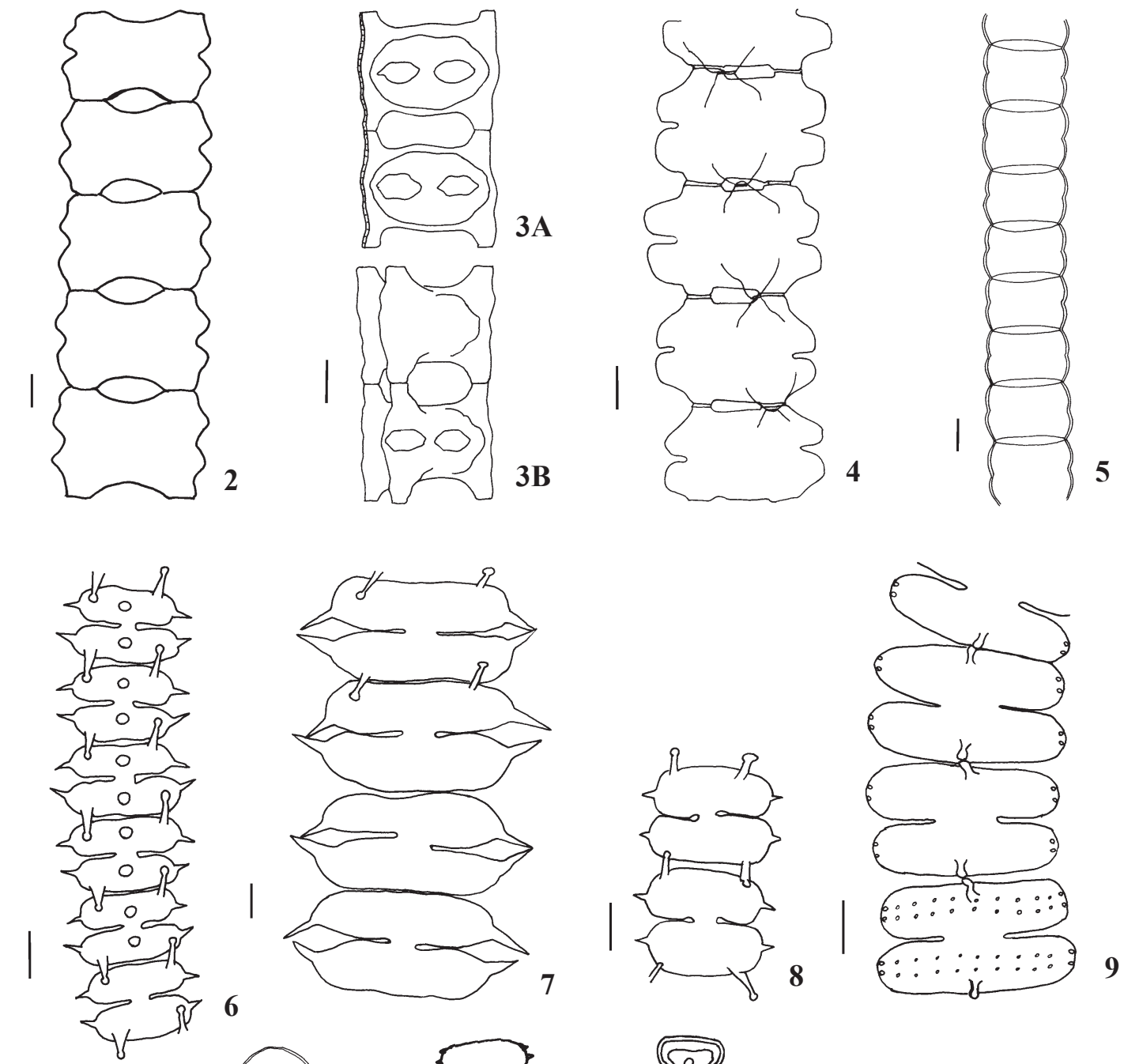

3B
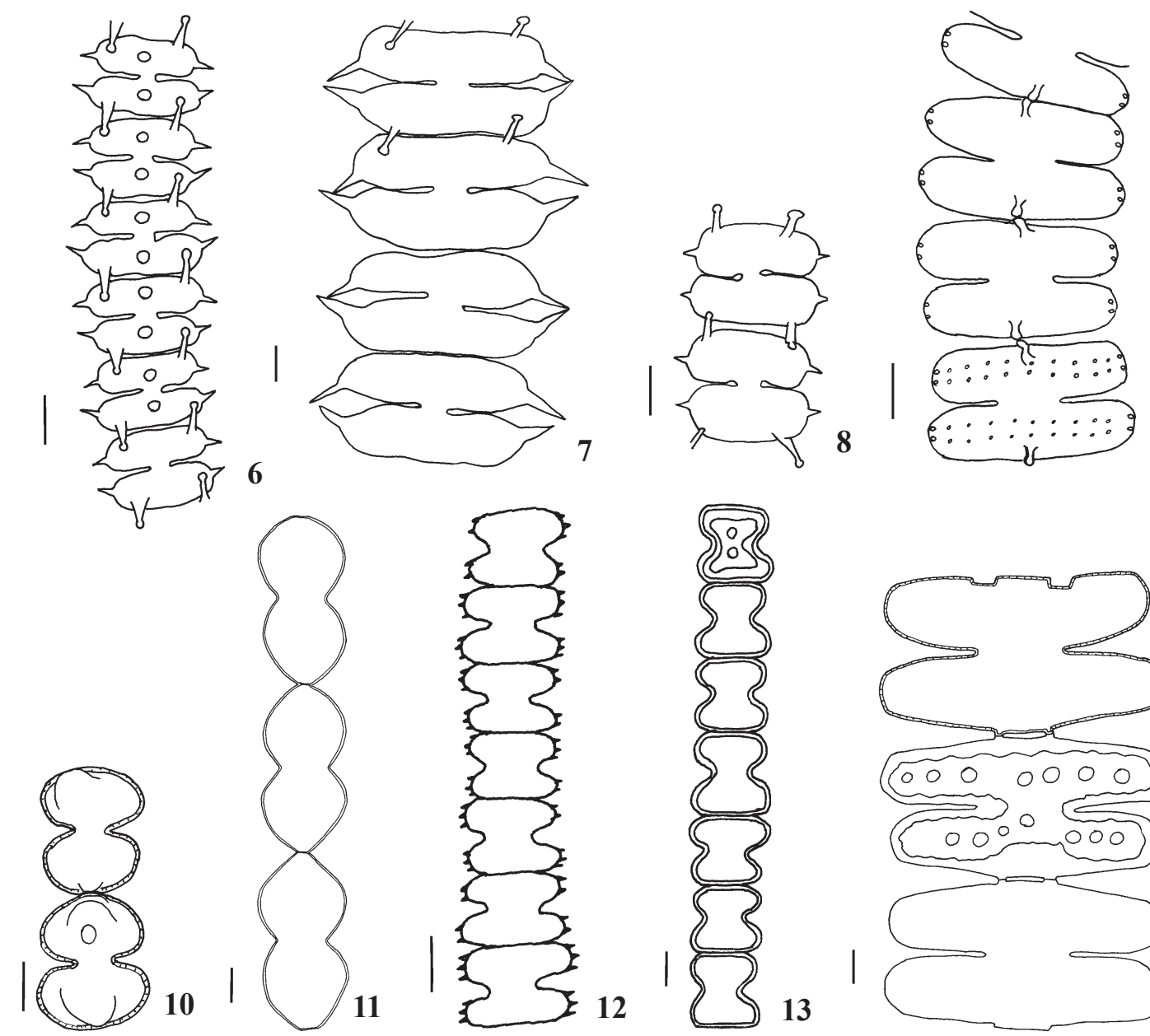

10
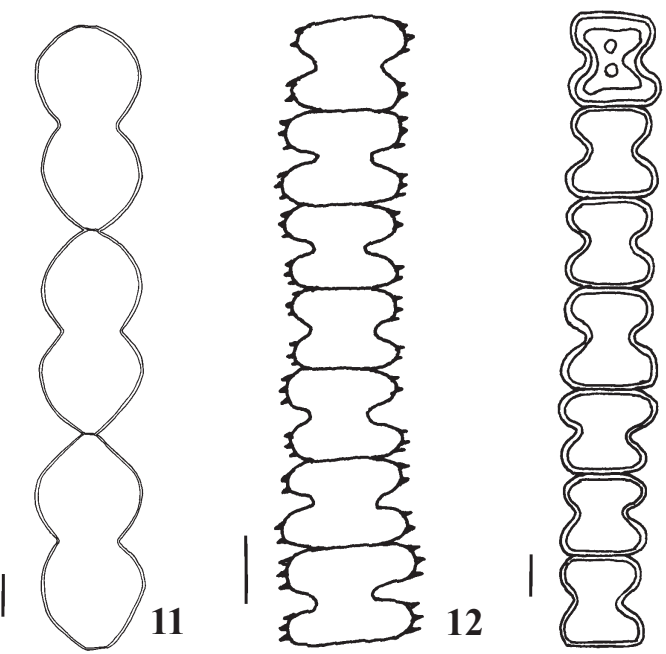

13

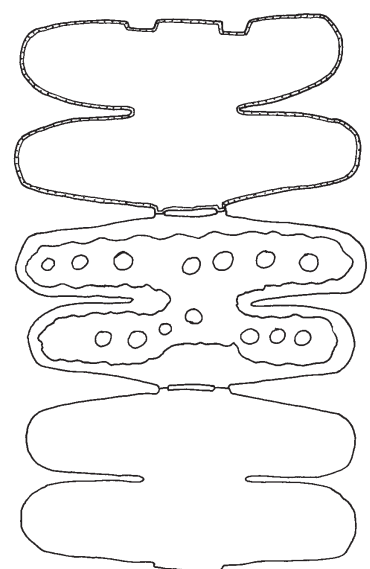

14

Figuras 2-14. 2. Desmidium aptogonum. 3A-B. D. baileyi. 4. D. pseudostreptonema. 5. Hyalotheca dissiliens. 6. Onychonema laeve var. laeve. 7. O. laeve var. latum. 8. O. laeve var. rectangulare. 9. Sphaerozosma aubertianum. 10. Spondylosium moniliforme. 11. S. panduriforme var. limneticum. 12. S. papillosum. 13. S. planum. 14. S. pulchrum. Barra $=10 \mu \mathrm{m}$.

Figures 2-14. 2. Desmidium aptogonum. 3A-B. D. baileyi. 4. D. pseudostreptonema. 5. Hyalotheca dissiliens. 6. Onychonema laeve var. laeve. 7. O. laeve var. latum. 8. O. laeve var. rectangulare. 9. Sphaerozosma aubertianum. 10. Spondylosium moniliforme. 11. S. panduriforme var. limneticum. 12. S. papillosum. 13. S. planum. 14. S. pulchrum. Bar $=10 \mu \mathrm{m}$. 
Hyalotheca dissiliens (Smith) Brébisson in Ralfs, Brit. Desm., 51, pl. 1, fig.1. 1848. 三 Conferva dissiliens Smith, Bot. Brit. Plants, 35: 2464. 1812.

Figura 5

Filamento não torcido; célula 13-17 × 19-28 $\mu \mathrm{m}$, 1,3-1,7 vezes mais larga que longa; constrição mediana rasa; semicélulas retangulares, margens laterais convexas; células unidas por seus ápices formando filamentos constritos nas junções; parede celular lisa.

Material examinado: BRASIL. ParanÁ: Euclides da Cunha: Reservatório de Rosana, 10-IV-2002, S.A. Felisberto s.n. (HUM15363); Rosana: Reservatório de Rosana, 29-VIII-2002, S.A. Felisberto s.n. (HUM15367).

Onychonema laeve Nordstedt var. laeve, Vidensk. Medd. Naturh. Foren. Kjöbenhavn (14/15): 206, pl. 3, fig.34. 1869.

Figura 6

Filamentos torcidos; célula 12,6-17,6 × 17,7-26 $\mu \mathrm{m}$, largura do istmo 2,2-3,3 $\mu \mathrm{m}, 1,5$ vezes mais larga (sem espinho) que longa; constrição mediana profunda, seno aberto; semicélulas oblongas, margem superior truncada com 2 processos unindo as células, margens laterais com 1 espinho, convergente; parede celular lisa.

Material examinado: BRASIL. PARANÁ: Rosana: Reservatório de Rosana, 11-IV-2002, S.A. Felisberto s.n. (HUM15364); 29-VIII-2002, S.A. Felisberto s.n. (HUM15367).

Onychonema laeve Nordstedt var. latum West \& West, Trans. Linn. Soc. London, Bot. II, 5(5): 232. pl. 12, fig. 18. 1896.

Figura 7

Filamento não torcido; célula 20-20,4 × 28-35,7 $\mu \mathrm{m}$ (sem espinhos e processos), largura do istmo: 4,2-5,7, espinho: 4,25-7,14 $\mu \mathrm{m}, 1,4-1,7$ vezes mais larga que longa; constrição mediana profunda, seno linear, abrindose distalmente, acutangular; semicélulas oblongofusiformes, margem superior reta, arqueada em direção aos ângulos espiníferos, estes com 1 espinho curto, pontiagudo, convergente; 2 processos curtos unindo as células; parede celular finamente pontuada.

Comentários: Difere da variedade típica por apresentar maior largura da célula, conforme Croasdale et al. (1983).

Material examinado: BRASIL. PARANÁ: Euclides da Cunha: Reservatório de Rosana, 10-IV-2002, S.A. Felisberto s.n. (HUM15363); 28-VIII-2002, S.A. Felisberto s.n. (HUM15366).
Onychonema laeve Nordstedt var. rectangulare Grönblad, Acta Soc. Scien. Fennicae, Ser. B., II, no 61945.

Figura 8

Filamento não torcido; célula 16-19 × 18,4-23 $\mu \mathrm{m}$ (sem espinho), largura do istmo: 2,6-5, espinho: 2-3 $\mu \mathrm{m}, 1,1-1,3$ vezes mais larga que longa, constrição mediana profunda, seno fechado distalmente; margem superior reta com processos curtos unindo as células, margens laterais com espinho curto; parede celular aparentemente lisa.

Comentários: Onychonema laeve var. rectangulare difere da variedade típica por apresentar relação comprimento/largura menor e espinhos mais curtos, de acordo com Croasdale et al. (1983), Grönblad (1945) e Sophia \& Dias (1996).

Material examinado: BRASIL. PARANÁ: Rosana: Reservatório de Rosana, 11-IV-2002, S.A. Felisberto s.n. (HUM15364); 29-VIII-2002, S.A. Felisberto s.n. (HUM15367).

Sphaerozosma aubertianum West, Trans. Linn. Soc. London, Bot., II, 5(5): 230. 1896.

Figura 9

Filamento torcido; célula $14,4-15 \times 19-28 \mu \mathrm{m}$, largura do istmo: 7,2-8 $\mu \mathrm{m}, 1,3-1,8$ vezes mais larga que longa; constrição mediana profunda, seno aberto; semicélulas oblongas; margens de células adjacentes conectadas por processo curto, posicionado na região mediana; margens superior e laterais arredondas; duas fileiras horizontais de poros estendido por toda a parede, na região mediana da semicélula.

Comentários: De acordo com Croasdale et al. (1983) S. aubertianum var. archeri, difere da variedade típica por apresentar duas fileiras de grânulos marginais em toda a extensão da semicélula. Os autores comentam ainda que estes grânulos podem ser apenas extrusões por poros, podendo apresentar indivíduos transicionais em relação à espécie tipo. West \& West (apud Croasdale et al. 1983) sugerem que $S$. aubertianum e $S$. aubertianum var. archeri sejam provavelmente sinônimos. Desta forma, optou-se por identificar este táxon apenas como $S$. aubertianum, principalmente por não ter sido possível realizar uma análise populacional, embora nos poucos exemplares encontrados ocorreu a dupla fileira de grânulos.

Material examinado: BRASIL. PARANÁ: Rosana: Reservatório de Rosana, 29-VIII-2002, S.A. Felisberto s.n. (HUM15367). 
Spondylosium moniliforme Lundell, Nova Acta Reg. Soc. Sci. Upsaliensis, III, 8(2): 92. pl. 5, fig. 16. 1871.

Figura 10

Filamento torcido; célula 20-26,4 × 15-20,6 $\mu \mathrm{m}$, largura do istmo: 7-9,6 $\mu \mathrm{m}, 1,2-1,4$ vezes mais longa que larga; constrição mediana profunda, seno aberto, acutangular; semicélulas oblongas, margem superior e laterais arredondadas; parede celular pontuada.

Material examinado: BRASIL. PARANÁ: Euclides da Cunha: Reservatório de Rosana, 10-IV-2002, S.A. Felisberto s.n. (HUM15363); Rosana: Reservatório de Rosana, 29-VIII-2002, S.A. Felisberto s.n. (HUM15367).

Spondylosium panduriforme (Heimerl) Teiling var. limneticum (West \& West) Förster, Archiv für Hydrobiologie, Supplement 63(4): 377. 1983. $\equiv$ Cosmarium moniliforme (Turpin) Ralfs var. limneticum West \& West, p. 23, t. 67, fig. 6-7. 1908.

Figura 11

Filamento não-torcido; célula 40,8-55,3 × 22-29$9 \mu \mathrm{m}$, largura do istmo: 11,2-17,8 $\mu \mathrm{m}, 1,5-2$ vezes mais longa que larga, unidas pela margem apical angulosa da célula; constrição mediana rasa, alongada, seno arredondado; semicélulas circulares, margem apical elevada na porção mediana, margens laterais arredondadas; parede celular lisa, espessa, com ampla mucilagem.

Comentários: No material examinado todos os exemplares, as dimensões celulares quanto ao comprimento apresentaram-se maiores que as da literatura, porém foram semelhantes ao material analisado por Sophia \& Dias (1996), conferindo também com a ilustração. Os autores comentaram que $S$. panduriforme var. limneticum diferencia-se de Cosmarium moniliforme (Turpin) Ralfs (com a qual pode ser confundida quando analisada em células isoladas), por possuir seno arredondado, istmo largo e alongado, parede espessa e cloroplasto loboestelóide no primeiro. Neste estudo, os espécimes foram examinados por meio de filamentos e não como células isoladas, e ainda apresentando todas as características correspondentes àquelas de $S$. panduriforme var. limneticum. Sophia \& Dias (1996) comentaram sobre a revisão e validação de nomes de desmídias realizada por Förster em 1983, quando este autor elevou a forma limneticum West \& West à categoria de variedade, considerando a maior largura da semicélula e a diferença entre as metades das semicélulas.

Material examinado: BRASIL. PARANÁ: Rosana: Reservatório de Rosana, 11-IV-2002, S.A. Felisberto s.n. (HUM15364); 29-VIII-2002, S.A. Felisberto s.n. (HUM15367).

Spondylosium papillosum West \& West, Trans. Linn. Soc. London, Bot., II, 5(2): 43. pl. 9, fig. 19. 1895.

Figura 12

Filamento não torcido; célula 8-9 × 9-12 $\mu \mathrm{m}$, largura do istmo: 5-6 $\mu \mathrm{m}, 1-1,1$ vezes mais larga que longa, as vezes tão larga quanto longa; constrição mediana profunda, seno amplamente aberto; semicélulas oblongas, células unidas pela justaposição das margens superiores, margens laterais arredondadas com espinhos pequenos (papilas).

Comentários: Spondylosium papillosum morfologicamente pode ser confundido com S. planum, tanto quanto à forma quanto às medidas celulares. Porém no primeiro as células são mais largas que longa ou as vezes tão larga quanto longa, apresentando espinhos pequenos nas margens laterais.

Material examinado: BRASIL. PARANÁ: Rosana: Reservatório de Rosana, 11-IV-2002, S.A. Felisberto s.n. (HUM15364).

Spondylosium planum (Wolle) West \& West, J. Linn. Soc., sér. Bot., 40: 430. 1912. इSphaerozosma pulchrum Bailey var. planum Wolle, Desm. Unit. States list Amer. Pediastrum, 1884.

Figura 13

Filamento não torcido; célula 9-13,3 × 8-12,5 $\mu \mathrm{m}$, largura do istmo: 4-6 $\mu \mathrm{m}, 1-1,1$ vezes mais longa que larga ou quadrática, células unidas pela justaposição das margens superiores; constrição mediana profunda, seno aberto; semicélulas oblongas, margem superior reta, margens laterais arredondadas; parede celular lisa.

Material examinado: BRASIL. PARANÁ: Rosana: Reservatório de Rosana, 11-IV-2002, S.A. Felisberto s.n. (HUM15364).

Spondylosium pulchrum (Bailey) Archer var. pulchrum, Pritchard's Infusoria 724. 1861. 三 Sphaerozosma pulchrum Bailey in Ralfs, Brit. Desm. 209, pl. 35, fig. 2. 1848.

Figura 14

Filamento torcido; célula $31,2-34 \times 60-68 \mu \mathrm{m}$, largura do istmo $18-24 \mu \mathrm{m}, 1,9-2,0$ vezes mais larga que longa, unidas por processos cilíndricos; constrição mediana profunda, seno mediano aberto; semicélula oblonga, margem apical com uma elevação formando um processo cilíndrico, conexão truncada entre células 
adjacentes, margens laterais amplamente arredondadas ou retas, assimétricas; parede celular pontuada.

Material examinado: BRASIL. PARANÁ: Rosana: Reservatório de Rosana, 29-VIII-2002, S.A. Felisberto s.n. (HUM15367).

Dentre os 13 táxons inventariados (tabela 1), Sphaerozosma aubertianum e Spondylosium pulchrum foram exclusivos da região lacustre no inverno, enquanto S. papillosum e S. planum foram exclusivos da região lacustre no outono. Desmidium aptogonum, D. baileyi, Onychonema laeve var. laeve, O. laeve var. rectangulare e Spondylosium panduriforme var. limneticum ocorreram na região lacustre de ambos os períodos estudados. Já Onychonema laeve var. latum foi exclusivo da região intermediária em ambos os períodos (outono e inverno).

Considerando os dois períodos amostrados, na região lacustre foi registrado maior número de táxons (12), sendo oito no outono e 10 no inverno. Independente da época de coleta, na região fluvial não houve ocorrência de desmídias pseudofilamentosas, nem na região intermediária no período do outono.

Agradecimentos - Aos biólogos e técnicos do Núcleo de Pesquisa em Limnologia, Ictiologia e Aqüicultura (Nupélia). À Companhia Paranaense de Energia (Copel) pelo suporte logístico e ao CNPq pela concessão da bolsa de mestrado para S. A. Felisberto e bolsa de pesquisa para L. Rodrigues.

\section{Referências Bibliográficas}

BICUDO, C.E.M., BICUDO, D. DE C., CASTRO, A.A.J. \& PICELLI-VICENTIM, M.M. 1992. Fitoplâncton do trecho a represar do rio Paranapanema (Usina Hidrelétrica de Rosana), Estado de São Paulo, Brasil. Revista Brasileira de Biologia 52:293-310.

BICUDO, D. DE C., BICUDO, C.E.M., CASTRO, A.A.J. \& PICELLI-VICENTIM, M.M. 1993. Diatomáceas (Bacillariophyceae) do trecho a represar do rio Paranapanema (Usina Hidrelétrica de Rosana), Estado de São Paulo, Brasil. Hoehnea 20:47-68.

BICUDO, C.E.M. \& MENEZES, M. 2006. Gêneros de algas de águas continentais do Brasil. Rima, São Carlos. p.1512.

BIOLO, S., SIQUEIRA, N.S., BORTOLINI, J.C. \& BUENO, C.B. 2008. Desmidiaceae (exceto Cosmarium) na comunidade perifítica em um tributário do Reservatório de Itaipu, Paraná, Brasil. Revista Brasileira de Biociências 6:8-10.
BORTOLINI, J.C., MORESCO, C., SIQUEIRA, N.S., BIOLO, S., MEURER, T. \& BUENO, N.C. 2008. Desmidiaceae do Lago Municipal de Cascavel, Paraná, Brasil. Revista Brasileira de Biociências 6:19-21.

CROASDALE, H., BICUDO, C.E.M. \& PRESCOTT, G.M. 1983. A synopsis of North American desmids, 2: Desmidiaceae: Placoderm. Section 5. The filaments genera. University of Nebraska Press, Lincoln. p.1-117.

DE LAMONICA-FREIRE， E.M. 1992. Desmídias filamentosas (Zygnemaphyceae, Desmidiales) da Estação Ecológica da Ilha de Taiamã, Mato Grosso, Brasil. Acta Limnologica Brasiliensis 4:315-325.

FELISBERTO, S.A.\& RODRIGUES, L. 2008. Desmidiaceae, Gonatozygaceae e Mesotaeniaceae na comunidade perifítica do reservatório de Salto do Vau (Bacia do Rio Iguaçu, PR). Hoehnea 35:235-254.

FÖRSTER, K. 1969. Amazonische Desmidieen, 1. Areal Santarém. Amazoniana 2:5-116.

FÖRSTER, K. 1974. Amazonische Desmidieen. 2 Areal Maués-Abacaxis. Amazoniana 5:135-242.

FÖRSTER, K. 1982. Conjugatophyceae: Zygnematales und Desmidiales (excl. Zygnemataceae). In Das Phytoplankton des Süsswassers: Systematik und Biologie (G. Huber-Pestalozzi, ed.). Schweizerbart'sche Verlagsbuchhandlung, Stuttgart, p.1-543.

GRÖNBLAD, R. 1945. De algis brasiliensibus praecipue Desmidiaceis in regione inferiore fluminis Amazonas. Acta Societatis Scientiarum Fennicae: nova série. B 2:143.

HORNE, A.J. \& GOLDMAN, C.R. 1994. Limnology. $2^{\text {ed }}$ McGraw Hill International, Singapore.

LOWE, R.L. \& PAN, Y. 1996. Benthic algal communities as biological monitors. In Algal ecology: freshwater benthic ecosystems (R.J. Stevenson, M.L. Bothwell \& R.L. Lowe, eds.). Academic Press, San Diego, p.705-739.

ROUND, F.E. 1983. Biologia das algas. Editora Guanabara Dois, Rio de Janeiro.

SOPHIA, M.G. 1982. Desmidiaceae (Zynemaphyceae) do município do Rio de Janeiro e arredores: uma contribuição ao seu conhecimento. Dissertação de mestrado, Universidade Federal do Rio de Janeiro, Rio de Janeiro.

SOPHIA, M.G. 1984. Contribuição ao conhecimento da flora ficológica da Lagoa de Juturnaíba, RJ, Brasil: Desmidiaceae (Zygnemaphyceae) de hábito filamentoso. Bradea 4:81-90.

SOPHIA, M.G. (1987). Contribuição ao conhecimento das desmídias de hábito filamentoso do estado do Rio de Janeiro, Brasil. Rickia 14:21-35.

SOPHIA, M.G. \& DIAS, I.C.A. 1996. Algas de três ambientes de águas claras do município de Parintins, Estado do Amazonas: Oedogoniophyceae e Zygnemaphyceae. Hohenea 23:59-80. 